\section{Masquerading Sanity: Crimes, Violence and Victimization on the Internet}

\section{Abstract}

The world of cybercrime has transformed significantly over the past ten or twenty years. Early concerns focused on the vulnerability of the financial industry, including the crimes of identity theft and hacking. However, in recent years, cybercrime has evolved to include crimes of harassment, child pornography, rape, "cyberterrorism" and even murder. This work examines an emerging form of violent crime involving the internet: Social Media Victim Targeting Networks (SVTN). The anonymity and limited available law enforcement on social media sites leaves predators with a large pool of vulnerable victims provide predators a new way to display and strengthen their criminological tendencies. The authors will discuss some of the expansion of victim targeting networks to popular Internet social networking sites using case examples that help develop concepts to better understand, prevent, and investigate the behavior. Based upon this, recommendations for future research related to this very serious and challenging behavior are noted.

Keywords: Criminality; Social media; Homicides; Psychosexual

\section{Heath Grant ${ }^{1}$ and Cathryn Lavery²}

1 Department of Law \& Police Science, John Jay School of Criminal Justice/ CUNY, USA

2 Department of Criminal Justice and Sociology, lona College, USA

Corresponding author: Cathryn Lavery

”CLavery@iona.edu

Chair and Professor, Department of Criminal Justice and Sociology, lona College, USA.

Tel: (914) 633-2597

Citation: Grant H, Lavery C. Masquerading Sanity: Crimes, Violence and Victimization on the Internet. 2017, 3:3.

\section{The Internet and a New Criminality}

The cases have multiplied exponentially. It is common now for people to read about crime directly associated with social media and the internet. In 2014, twenty-eight year old Daniel Zeitz was shot and killed when he met with potential buyers of his Xbox from Craigslist [1]. Richard Beasley and his teen accomplice, Rafferty were convicted of luring three men into a wooded area in Ohio under the pretence of false job postings and then killing them. Back in 2007, nineteen year old Michael John Anderson pretended to be a woman seeking a babysitter. When the victim Katherine Olson answered his post, Anderson shot her and placed her in the trunk of a car and consequently abandoned it. Anderson was considered to be the first "Craigslist Killer" [2]. Of course, in 2010, the new "Craigslist Killer", Philip Mark off was arraigned on murder charges for the brutal slaying of Julissa Brisman as well as two additional assaults. All victims were found on Craigslist [3]. Similarly, the as yet unsolved case involving the Long Island Serial Killer murdered four prostitutes from Craigslist. Criminologist Jack Levin has stated, "Thanks to Craigslist in particular, 'stranger' homicides have been on the increase" [4].

Social media has permanently changed the shape and mode of communication in the world. Outlets such as Facebook, Craigslist, Snapchat, etc. have not only made the world smaller, but also provided us with a false sense of security. A "Friend" on Facebook that one may not know formally will engage in lengthy discussions threads like old friends. Dating sites like Match.com, OKCupid.com, and Lavalife.com match individuals based on likes and personality characteristics. This can give someone an idea that they already have so much in common. This "comfortability" can lead a person to ignore warning signs and safety recommendations by cyber experts. Since John Edward Robinson [4], the Internet's First Serial Killer, responsible for over eight homicides linked to the internet, society has seen the growth of a variety of crimes and offenders emerging from the internet.

Over 100 murders have been linked to Craigslist alone [5]. Eightyone percent of internet-initiated crimes involve social networking sites, with $78 \%$ of burglars using social media sites as their platform to scope victims. In other words, social media sites have become the preferred Victim Targeting Network (VTN) of some due to its anonymity and ease of access. Thirty-three percent of internet-initiated sex crimes were linked with social media and in particular, dating sites. James Brown has been accused of allegedly killing four women he met on Backpage.com. With regards to sex crimes and minors, it has been recorded that $76 \%$ of a juvenile or adolescent's first contact with a predator occurred in a chat 
room. Eleven percent of adolescents have shared naked pictures of themselves online or with text messages, with many believing the person they send to does not share that information with anyone else. There are currently estimated over 750,000 child sexual predators online worldwide since 2012 [6-8].

\section{Why are So Many Participating in Criminality Online?}

The concept of anonymity is a powerful tool online. Predators can engage, have conversations with, lure and set up meetings with victims by lying about their profiles and who they really are and what their true intents are. There is a vulnerable supply of victims available for them. Social media apps such as Grinder and Tinder offer an explicitly anonymous forum to strangers for casual encounters. When a first meeting is experienced online, there is no face-to-face interaction, so it is not possible to calculate and observe body language. Without the important cues of voice, tone, and other physical gestures, a possible victim is more likely to interpret what they perceive as true.

The web offers unique opportunities for a sexually deviant person. There is open access to chatrooms, pornography and sex workers who advertise. Many of individuals, otherwise characterized as sexual deviants feel comfortable expressing themselves and experimenting online. In 2016, Brady Oestrike of Michigan, tortured and murdered Brooke Slocum who was only 18 and 8 months pregnant and her boyfriend, Charles Oppenneer, after Oppenneer answered an ad on Craigslist for a sexual encounter [9]. After the investigation, it was found that Oestrike's home was a torture den with his victims brutalized for days prior to their murders. Police continue to investigate whether or not Oestrike is connected to any other sex crimes from social media sites. John Katehis, age 16, and a self-proclaimed Satanist placed an ad offering "kinky sex". Radio caster George Weber answered the ad in 2009. Katehis admitted he was offered $\$ 60.00$ by Weber for participating in a foot fetish (binding his feet in duct tape) and pnigophilia (smothering). Katehis stabbed Weber over fifty times, in which he claimed was accidental. He was convicted of second degree murder in 2011 [2].

Psychosexual disorders or paraphilias are characterized by sexual fantasies involving a non-human object, non-consenting partner or pain and/or humiliation of oneself or a partner, like fetishism or sadomasochism [6]. Beckham and Prohaska [3] studied deviant men who solicit sex workers and killed them. In their results, they found that offenders examined had personality disorders with psychopathic traits as well as extreme sexual deviance. The offenders never used drugs or alcohol and the offenders' psychopathic traits were very similar: Unstable homes, neglect and/or abuse in early childhood, no valid emotional attachments in relationships and a 'charming' or seductive affect with people [3].

Research has examined whether or not psychopaths or sociopaths spend an inordinate amount of time on the internet. Buckels et al. [10] examined patterns of trolling the internet; in other words, using social media as the preferred victim targeting network. They saw a correlation between the behavior and the
Dark Tetrad of Personality: narcissism, sadism, psychopathy (anti-social personality disorder) and Machiavellianism.

Internet using psychopaths have been categorized into a continuum of predatory behavior. iPredopaths [11], a term identified in 2012, is "an information age criminological and human consciousness constructs replacing the pre-information age of sociopathy and psychopathy" [12]. It is a character disorder where an individual uses information technology and their savvy to identify, stalk, troll, and manipulate their victims. It is deduced by Nuccitelli [9] that many iPredopaths have no remorse, guilt and shame and finds the internet a playground for their deviant and criminal behavior. Nuccitelli also identifies two other typologies: the iPredator and Doctus iPredopath. The iPredator gains selfimportance, power and uses the anonymity of cyberspace to rationalize their actions. A Doctus iPredopath are high skilled psychopaths who engage in not only manipulating, exploiting but victimizing their targets both online and offline.

The use of social media victim targeting networks is not limited to males. In 2009, in Oregon, Korena Roberts purposely answered an online ad requesting baby clothes. She went to meet the very pregnant Heather Snively at her apartment. Roberts beat Snively to death and removed the fetus from her womb. She hid Snively in a crawl space and told the police the baby was hers. When it was apparent that she had not given birth, along with residual evidence left at the crime scene, she was arrested and sentenced to life in prison. The baby did not survive [2]. In California, Alix Catherine Tichelman pleads "not guilty" to the death of Timothy Hayes, a Google Ad Executive twice her age. Tichelman gave Hayes an injection of heroin and allegedly watched him die. They met on the website Seeking Arrangement, which states it is the leading "Sugar Daddy" /"Sugar Baby" dating site with over three million members. Some women make arrangements for financial assistance which can range from $\$ 500.00-\$ 5000.00$ a month. The payments are viewed as an "allowance". The notion of whether this is a form of prostitution is an on-going debate. There have been additional accusations of ranging from sexual assault, burglaries and other crimes stemming from these types of sites [12].

\section{The 'Dark Net' Goes Deep}

The Dark Net is considered the 'belly of the beast'. It is the portion of the internet that "is intentionally hidden from the search engines, uses masked IP addresses and is accessible only with a special browser, Tor" [13]. In 2011, Silk Road, a site that appeared on the Dark Net, was an illegal version of EBay, Craigslist, etc. Silk Road was named specifically after the historical trading route which initially carried goods between the East and the West. This site's goals connected consumers to sellers of drugs, sex, and even assassins for hire [14]. By 2012, Silk Road's site operators were making approximately $\$ 90,000.00$ a month. The site's creator and administrator, Ross Ulbricht was arrested in 2013 and the site was immediately removed. Even though Ulbricht was convicted of drug trafficking, money-laundering and attempted murder, a month later Silk Road 2.0 emerged and within weeks jumped to 8 million dollars in sales. That site was removed by 
the government; not surprisingly, the 3.0 model came sooner after and the cycle continues [15]. According to a University of Portsmouth study in 2014, child pornography is the most sought after in terms of content, followed by the illegal weapons trade, drugs and stolen identities [16].

\section{Where Does This Leave Us?}

The Dark Web presents communities with a myriad of problems and challenges to law enforcement, in particular. Law enforcement needs to continue vigilant patrolling of the internet, especially sexual criminality. Social media gives us an open access to potential victims. Child predators "groom" their victims by falsely presenting themselves or using compliments and encouragement. In Texas, four men used Grindr to entrap gay men by falsely portraying themselves as homosexuals and then beating and robbing their victims [17]. However, without clear profiles of victim and offender behavior, law enforcement have very little to proactively work from in forums as vast as the Dark Web [18]. In addition, since prostitution has evolved to make much more extensive use of the internet, there are substantial problems with monitoring, those crimes as well as the litany of associated criminalities. Images and videos of extreme violence draw deviant individuals to look to the internet for this catalyst [19]. Better screening for dating sites and warning recommendations and protocols for users of these sites can be monitored by administrators to help with crime prevention. This is an uphill battle for law enforcement, cybercrime experts and computer administrators.

\section{Conclusion}

More research and studies need to be done regarding this emerging use of social media as a preferred victim targeting network. Often typologies of crime can be seen as an academic exercise, supporting theory only and engaging in teaching and classroom discussions. The integral role of social media in our lives, as well as the seemingly increasing use of it as a hunting ground for predators of all sorts point to the need for more research on the profile and behavior of both victims and offenders in cyberspace. Although not necessarily politically correct, the victimology is also essential to validate, as these crimes often involve important seeking behaviors on the part of the victims. Early research on the more general serial murder phenomenon can be examine, tested and applied with internet predator typologies for significance or consideration as an investigative tool. 


\section{References}

1 Corbin C (2014) Beware Craigslist dangers, security experts warn.

2 Goad J (2014) Thirty killers who hunted for prey on craigslist.

3 Beckham K, Prohaska P (2012) Deviant men, prostitution \& the internet: A qualitative analysis of men who killed prostitutes whom they met online. IJCJS pp: 635-648.

4 Victims of Violence (2016) Crime on the internet.

5 Dewey C (2016) Think twice before answering that ad: 101 murders have been linked to craigslist. The Washington Post.

6 Burns G (2013) Prosecutor: Sterling Heights man killed four women he met through Backpage.com adult classifieds. MLive.

7 US DOJ (2017) Office of sex offender sentencing monitoring apprehend registering and trafficking.

8 Arrigo B, Purcell C (2001) Explaining paraphilias and lust murder: Toward an integrated model. Int J Offender Ther Comp Criminol 45 1-26.

9 Crimeinsider Staff (2016) Cops: Video shows craigslist killer preparing to hold pregnant teen captive. Crimeinsider: CBS/AP.
10 Buckels E, Trapnell PD, Paulhus DL (2014) Trolls just want to have fun. Personality \& Individual Differences 67: 97-102.

11 Nuccitelli M (2016) iPredator, iPredopath \& Doctus iPredopath.

12 Payne E, Lah K (2014) Yacht killing case shines light on 'sugar daddy' websites. CNN.

13 Solomon J (2016) The deep web vs. the dark web.

14 Jardine E (2015) The dark web dilemma: tor, anonymity and online policing. Global Commission on Internet Governance 21: 1-24.

15 Dredge S (2014) Study claims more than $80 \%$ of dark net traffic is to child abuse sites. Raw Story.

16 Boroff D (2017) Four Texas men accused of assaulting gay men in their homes used grindr to targey their victims. The Daily News.

17 Goldbeck J (2014) Internet trolls are narcissistic, psychopaths \& sadists. Psychology Today.

18 Goldstein S (2015) Georgia couple missing after craigslist meet up to buy car. The Daily News.

19 Greig C (2005) Evil serial killers: In the minds of monsters. Arcturus Publishers, NY, USA. 